\title{
Integrated Fuzzy ANP, Fuzzy VIKOR and goal programming for sourcing in a supply chain: A case study from cable industry
}

\author{
Masoud Rezaei $^{a^{*}}$, Mahdi Abedini Naeeni ${ }^{\mathrm{b}}$ and Mohammad Sabet Motlagh
}

${ }^{a}$ Master of Science, CEO of GSK Industrial Clinic, Qom, Iran

${ }^{b}$ Master of Science, Department of Industrial Management, Tarbiat Modares University, Tehran, Iran

${ }^{c}$ Master of Science, Department of Industrial Management, Tehran University, Tehran, Iran

CHRON I C LE

\section{Article history:}

Received January 18, 2013

Received in revised format 10 May 2013

Accepted May 152013

Available online

May 162013

Keywords:

Sourcing

Fuzzy Analytic network process

Fuzzy VIKOR

Multi-objective mixed integer

nonlinear programming

\section{A B S T R A C T}

In today's competitive business environment, companies strive to increase their market shares. All companies clearly understand that they have to reach this goal by implementing cost effective methods and increase profits as much as possible. The cost of purchasing raw materials and component parts are significant portion of products in most manufacturing firms. Supplier selection and evaluation have been widely recognized to be one of the most substantial issues on material purchasing. In order to choose reliable suppliers it is necessary to have a trade-off between some tangible and intangible factors where some of them are in serious conflict. In this paper, an integrated technique of analytical network process improved by VIKOR and fuzzy sets theory and multi-objective mixed integer nonlinear programming is proposed to determine the appropriate suppliers. The proposed model of this paper also determines the order quantity allocated to each supplier in the case of multiple sourcing, multiple products and multi-period time horizon for an Iranian cable company.

(C) 2013 Growing Science Ltd. All rights reserved.

\section{Introduction}

Sourcing or supplier selection plays an important role on supply chain management. In recent years, determining the best supplier has become a key strategic consideration (Dobler, 1990; Liao \& Kao, 2011; Aghajani Bazzazi et al., 2011). The cost of raw materials and component parts includes a big portion of the cost of a product, most firms spend considerable amount of their revenues on purchasing (Kilincci \& Onal, 2011). Purchasing literature discloses that there are three major decisions associated with the sourcing problem including the product to order, the order size, the appropriate supplier to purchase and finally an appropriate schedule purchase plan. Many experts believe that the second question is the most important activity of a purchasing department (Willis et al., 1993; Chung et al., 2005). Allocating orders from suppliers plays an important role on managing the supply chain and it comes after supplier selection and evaluation (Hale \& Hamidi, 2011).

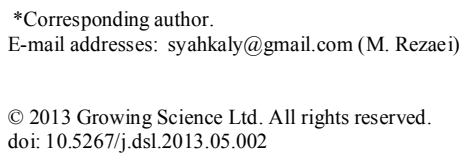


In general, supplier selection is a multi criteria group decision making (MCDM) problem and comprises tangible and intangible factors (Hassanzadeh Amin et al., 2011). This decision making process is normally involved with human judgment, thus crisp data do not seem sufficient to model these three judgments. Therefore, the ratings and weights of the criteria need to be assessed based on linguistic variables. Fuzzy Set Theory (FST) is as an efficient tool to handle this uncertainty efficiently and convert human judgments into meaningful results (Bellman \& Zadeh; Herrara \& Viedma, 2000).

This paper is organized as follows: The Section 2 cites the relevant literature to Supplier selection problem (SSP) in two parts including criteria and methods. The improved analytic network process (ANP) and VIKOR based on fuzzy sets theory are introduced in Section 3 and 4. In section 5, we describe supplier selection methodology and formulation of the multi-objective mathematical model. Section 6 presents a case study and solution methodology. Finally, Conclusion is given in Section 7.

\section{Literature review}

\subsection{Literature of criteria}

SSP decisions are normally involved with a complex process including various criteria, where some of these criteria are often in conflict with one another. For instance, low prices can be offset by poor quality or delivery reliability. The choice and the number of criteria to be included in the supplier selection process must be carefully determined to represent the competitive strategies of buying firm (Talluri \& Narasimhan, 2003). Dickson (1966) identified at least 23 criteria in his empirical investigation in various supplier selection problems. Quality, cost, and delivery performance history are identified as the most important criteria in supplier selection. Roa and Kiser (1980) and Bache et al. (1987) identified, respectively, 60 and 51 criteria for supplier selection. Evaluation and ranking of potential suppliers involves both tangible and intangible criteria. Weber et al. (1991) classified all published papers (since 1966) based on some criteria and identified quality, cost and on-time delivery as the most important supplier selection criteria for evaluating supplier performance. Production facilities and capacity, technical capability and geographical location were also detected as important criteria. Choi and Hartley (1995) presented 26 supplier selection attributes from a survey on US automotive companies. Lin and Chen (2004) did a comprehensive review of literature and identified 183 decision attributes for evaluating candidate supply chain alliances for general industries. These attributes were further categorized into eight aspects. Hu (2004) analyzed 24 papers published after 1991 and discovered that price, quality, production capacity and delivery remained as the most important attributes of supplier evaluation techniques. In order to be more practical when selecting suppliers, Çebi \& Bayraktar (2008) presented 37 criteria and presented a theory where it integrated neural network and data envelopment analysis for evaluation of supplier under incomplete information of evaluation criteria. Lee (2009) presented 44 criteria on the hierarchical model for ranking suppliers in the TFT-LCD industry and classified 39 detailed criteria, based on 4 main criteria including cost, benefits, opportunities and risks and 11 sub-criteria. Bo van der Rhee et al. (2009) empirically studied how manager trade-off between cost, delivery, flexibility and service features in the supplier selection process for commodity raw materials, given acceptable quality. Most of the discussed articles suggested that managers have been perceived quality, cost, delivery performance, geographical location and flexibility are most important supplier selection criteria.

\subsection{Literature of methods}

Several methods have been proposed for evaluation and order allocation. Some of these as 55 follow: An integrated AHP and preemptive goal programming based on multi-criteria decision making (MCDM) methodology was developed by Wang et al. (2004) to select the best set of multiple suppliers to satisfy capacity constraint. Kumar et al. (2006) presented a fuzzy Multi-objective Integer 
Programming model, which incorporates cost-minimization, quality-maximization and maximization of on-time delivery goals with the buyers, demand and suppliers capacity constraints (Gwo-Hshiung et al., 2011). Ha and Krishnan (2008) proposed a hybrid method, which incorporates AHP, DEA and Neural Network (NN) techniques into an evaluation process in order to select competitive suppliers in supply chain. Demirtas and Ustun (2008) proposed an integrated approach using analytic network process (ANP) with multi-objective mixed integer linear programming (MOMILP) to consider both tangible and intangible factors in selecting the best suppliers and to determine the optimum order quantity among selected suppliers to maximize the total value of purchasing and minimize the budget and defect rate. Guneri et al. (2009) developed an integrated model based on FST and linear programming. In this model, integration with linear programming enabled decision-makers to assign order quantities to each supplier considering the Total Value Purchase (TVP) maximizing objective. Amid et al. (2009) presented a fuzzy weighted additive and mixed integer linear programming method, which includes minimizing the net cost, minimizing the net rejected items and minimizing the net late deliveries objective functions with capacity and demand requirement constraints under price breaks in a supply chain. Awasthi et al. (2009) studied the supplier selection, purchase problem under stochastic demand by considering some limitation on minimum and maximum order sizes, and proposed a heuristic method for their model. Wu et al. (2009) presented an integrated multi-objective decision-making process by using analytic network process (ANP) (Yüksel \& Dagdeviren, 2007; Haleh \& Hamidi, 2011) and mixed integer programming (MIP) to optimize the selection of supplier.

In another work, the supplier selection was viewed as the problem of mining a large database of shipment. The proposed method incorporated the extended association rule algorithm of data mining with that of set theory to detect key suppliers (Lin et al., 2009). In another paper, the authors developed a model based on the attribute-based ant colony system (AACS) to construct a platform to examine the critical factors for decision making in a dynamic business environment in order to select the appropriate suppliers (Krajewski et al.,2007; Tsai et al., 2011). Liao and Kao (2011) proposed integrated fuzzy techniques for order preference by similarity to ideal solution (TOPSIS) and multichoice goal programming (MCGP) approach to determine the supplier selection problem. Vinodh et al. (2011) used fuzzy analytic network process (fuzzy ANP) approach for the supplier selection process. In another research, neural network based on supplier selection and supplier performance evaluation systems were presented (Aksoy \& Öztürk, 2011). Hale and Hamidi (2011) integrated a fuzzy MCDM to allocate suitable shares of orders to the best possible suppliers and fuzzy linear programming model to optimize the price, quality and risk objectives and satisfy a set of constraints in a supply chain. Amid et al. (2011) proposed a weighted max-min model for fuzzy multi-objective supplier selection in a supply chain where an analytic hierarchy process (AHP) was implemented to determine the weights of criteria. The proposed model helped decision maker (DM) find out the appropriate order to each supplier, and allowed the purchasing manager(s) to manage supply chain performance on cost, quality and service. Rezaei and Davoodi (2011) developed two multi-objective mixed integer non-linear models for multi-period lot-sizing problems involving multiple products and multiple suppliers. Each model was constructed based on three objective functions (cost, quality and service levels) and a set of constraints. They solved these models with Genetic algorithm. Shemshadi et al. (2011) extended the fuzzy VIKOR method with a mechanism to extract and deploy objective weights based on Shannon entropy concept in supplier selection problem.

\section{Fuzzy ANP}

The ANP can easily accommodate the interrelationships existing among the functional activities (Mohanty et al., 2005). In FANP, pair-wise comparison matrices are formed between each pairs of attributes at each level with the help of triangular fuzzy numbers. The concept of super matrices is employed to obtain the composite weights that overcome the existing interrelationships. The values of parameters are transformed into triangular fuzzy numbers and they are used to calculate fuzzy values. Furthermore, a scale of $\tilde{1}-\tilde{9}$ is used to state the preferences of the decision maker. This scale 
is shown in Table.1.

Table 1

Scale of Linguistic variable (Bojan \& Yvonilde,2008)

\begin{tabular}{lcl}
\hline Scale of respected fuzzy number & Fuzzy number & Linguistic variable \\
\hline$(1,1,1)$ & $\tilde{1}$ & identical \\
$(1,3,5)$ & $\tilde{3}$ & A little more important \\
$(3,5,7)$ & $\tilde{5}$ & more important \\
$(5,7,9)$ & $\tilde{7}$ & Much more important \\
$(7,9,9)$ & $\tilde{9}$ & strictly more important \\
$(\mathrm{x}-1, \mathrm{x}, \mathrm{x}+1)$ & $\tilde{2}, \tilde{4}, \tilde{6}, \tilde{8}$ & A value between 2 levels \\
$\left(\frac{1}{x+1}, \frac{1}{x}, \frac{1}{x-1}\right)$ & $1 / \tilde{x}$ & Inverse triangular numbers \\
\hline
\end{tabular}

To evaluate the decision-maker preferences, the $\mathrm{m} \times \mathrm{n}$ triangular fuzzy matrix is used. If $\tilde{A}$ is a pair-wise comparison matrix demonstrated in Eq. (1) as follows,

$$
\tilde{A}=\left(\begin{array}{cccc}
\left(a_{11}^{l}, a_{11}^{m}, a_{11}^{u}\right) & \left(a_{12}^{l}, a_{12}^{m}, a_{12}^{u}\right) & \ldots & \left(a_{1 n}^{l}, a_{1 n}^{m}, a_{1 n}^{u}\right) \\
\left(a_{21}^{l}, a_{21}^{m}, a_{21}^{u}\right) & \left(a_{22}^{l}, a_{22}^{m}, a_{22}^{u}\right) & \ldots & \left(a_{21}^{l}, a_{21}^{m}, a_{2 n}^{u}\right) \\
\vdots & \vdots & \vdots & \vdots \\
\left(a_{m 1}^{l}, a_{m 1}^{m}, a_{m 1}^{u}\right) & \left(a_{m 1}^{l}, a_{m 1}^{m}, a_{m 1}^{u}\right) & \ldots & \left(a_{m n}^{l}, a_{m n}^{m}, a_{m n}^{u}\right)
\end{array}\right)
$$

There are several techniques for getting estimates for the fuzzy priorities. One of these methods, the logarithmic leastsquares method (Ramik, 2007) is reasonable and effective and is used in this study. The logarithmic least squares method for calculating triangular fuzzy weights can be given as follows:

$\widetilde{W}_{\mathrm{k}}=\left(\mathrm{W}_{\mathrm{k}}^{\mathrm{l}}, \mathrm{W}_{\mathrm{k}}^{\mathrm{m}}, \mathrm{W}_{\mathrm{k}}^{\mathrm{u}}\right), \mathrm{k}=1,2,3, \ldots, \mathrm{n}$

where

$W_{k}^{s}=\frac{\left(\prod_{j=1}^{n} a_{k j}^{s}\right)^{1 / n}}{\sum_{j=1}^{n}\left(\prod_{j=1}^{n} a_{i j}^{m}\right)^{1 / n}}, \quad s \in\{l, m, u\}$

\section{Fuzzy VIKOR}

Based on the concept of fuzzy logic and the VIKOR method, the proposed fuzzy VIKOR method is developed. The procedure of FVIKOR consists of the following steps (Chen \& Wang, 2008):

Step 1: Generating feasible alternatives, determining the evaluation criteria, and setting a group of decision makers,

Step 2: Define linguistic variables and their corresponding triangular fuzzy numbers.

According to Chou \& Chang (2008) studies, a seven-scale linguistic variable fuzzy number is used. This linguistic scales and corresponding triangular fuzzy numbers for the rating of alternatives show in Table 2.

Table 2

Linguistic terms for the fuzzy rating

\begin{tabular}{ll}
\hline Linguistic terms & Corresponding Fuzzy numbers \\
\hline Very bad (VB) & $(0,0,1)$ \\
Bad (B) & $(0,1,3)$ \\
Medium bad (MB) & $(1,3,5)$ \\
Medium (M) & $(3,5,7)$ \\
Medium good (MG) & $(5,7,9)$ \\
Good (G) & $(7,9,10)$ \\
Very Good (G) & $(9,10,10)$ \\
\hline
\end{tabular}


Step 3: Integrate decision makers' preferences and opinions. The preferences and opinions of $n$ decision-maker with respect to $\mathrm{j}$ criterion for the ith alternative can be calculated by:

$\tilde{\mathrm{x}}_{\mathrm{ij}}=\frac{1}{n}\left(\sum_{e=1}^{n} \tilde{\mathrm{x}}_{\mathrm{ij}}\right), \mathrm{i}=1,2,3, \ldots, \mathrm{m}$

Step 4: Calculate fuzzy weighted average and construct the (normalized) fuzzy decision matrix (D):

$$
\begin{aligned}
& \widetilde{\mathrm{w}}=\left[\begin{array}{llll}
\widetilde{\mathrm{w}}_{1} & \widetilde{\mathrm{w}}_{2} & \ldots & \widetilde{\mathrm{w}}_{k}
\end{array}\right] \mathrm{j}=1,2,3, \ldots, \mathrm{k} \\
& C_{1} C_{2} \quad \cdots \quad C_{k}
\end{aligned}
$$

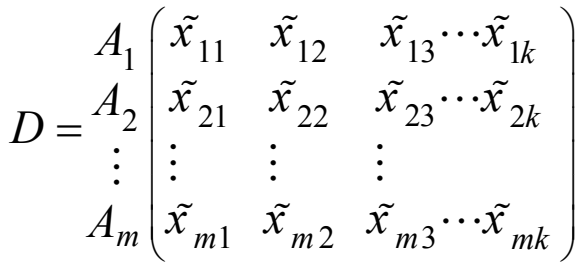

where $\widetilde{\mathrm{w}}_{\mathrm{j}}$ the important weight of the $\mathrm{jth}$ criterion is (is calculated by FANP).

Step 5: Determine the fuzzy best value (FBV) and fuzzy worst value (FWV):

$$
\tilde{f}_{j}^{*}=\max _{i} \tilde{x}_{i j}, \tilde{f_{j}^{-}}=\min _{i} \tilde{x}_{i j}
$$

Step 6: Calculate the values:

$$
\begin{gathered}
\tilde{S}_{i}=\sum_{i=1}^{k} \frac{\tilde{w}_{j}\left(\tilde{f_{j}^{*}}-\tilde{x_{i j}}\right)}{\left(\tilde{f_{j}^{*}}-\tilde{f_{j}^{-}}\right)} \\
\tilde{R}_{i}=\max _{j}\left[\frac{\tilde{w_{j}}\left(\tilde{f_{j}^{*}}-\tilde{x}_{i j}\right)}{\left(\tilde{f_{j}^{*}-\tilde{f}_{j}^{-}}\right)}\right]
\end{gathered}
$$

where $\widetilde{S}_{i}$ and $\widetilde{R}_{i}$ represent the utility measure and the regret measure, respectively, and $W_{j}$ is the weight of the jth criterion (Tong et al., 2005). In fact, $\widetilde{S}_{i}$ is $A_{i}$ with respect to all criteria calculated by the sum of the distance for the FBV, and $\widetilde{R}_{i}$ is $A_{i}$ with respect to the $j^{\text {th }}$ criterion, calculated by the maximum distance of FBV.

Step 7: Calculate the values of $\tilde{S}^{*} ; \tilde{S}^{-} ; \tilde{R}^{*} ; \tilde{R}^{-} ; \tilde{Q}_{i}$ :

$$
\begin{aligned}
& \tilde{S}^{*}=\min _{i} \tilde{S}_{i}, \tilde{S}^{-}=\max _{i} \tilde{S}_{i} \\
& \tilde{R}^{*}=\min _{i} \tilde{R}_{i}, \tilde{R}^{-}=\max _{i} \tilde{R}_{i} \\
& \tilde{Q_{i}}=v \frac{\left(\tilde{S}_{j}-\tilde{S}^{*}\right)}{\left(\tilde{S}^{-}-\tilde{S}^{*}\right)}+(1-v) \frac{\left(\tilde{R}-\tilde{R}^{*}\right)}{\left(\tilde{R}^{-}-\tilde{R}^{*}\right)}
\end{aligned}
$$

Here $v$ here means the weight of the strategy of the maximum group utility (Wu et al., 2009). When $\mathrm{v}>0.5$, the decision tends toward the maximum majority rule; and if $\mathrm{v}=0.5$, the decision tends toward the individual regret of the opponent. Hence, $v$ is introduced as weight of the strategy of 'the majority of attributes'. Usually, the value of $v$ is taken as 0.5 . However, $v$ can take any value from 0 to 1 (Bazzazi et al., 2011). Rank and improve the alternatives, sort by the values S, R, and Q, in decreasing order and reduce the gaps in the criteria and the best alternatives having the lowest value (Wu et al., 2009). 


\section{The proposed model in supplier selection and order allocation}

As mentioned in Introduction, multiple sourcing consists of two parts. This integrated approach proposes a two-stage mathematical model, which includes supplier evaluation and order allocation.

\subsection{Evaluation stage}

In the evaluation stage, the suppliers are evaluated according to 16 criteria that are involved in four control hierarchies. The steps of evaluation stage are described below in detail.

\subsubsection{Determine the criteria for supplier selection}

Determine the control hierarchies and their criteria for comparing the criteria and their sub criteria.

\subsubsection{Calculate the weights of the criteria by Fuzzy ANP}

Perform paired comparisons. Compare the criteria in a cluster in relation to their influence on a criterion in another cluster which they are connected to (or on elements in their own cluster).

\subsubsection{Compute the overall score of each supplier by Fuzzy VIKOR}

Synthesize the weights of the alternatives for all the criteria of control hierarchy. Do this for all criteria. Use the resulting fuzzy weights to compute the overall score of each supplier by Eq. (12).

$\mathrm{W}_{i}=($ low. med, high $)=\frac{\text { low }+4 \text { med }+ \text { high }}{6}$

\subsection{Shipment stage for order allocation}

A Multi-Objective mix integer nonlinear programming model is suggested in this stage. This model is described in detail in the following sections. 5.2.1. Build the Multi-Objective mix integer nonlinear programming model the objective functions and the constraints of this model are as follows (Khouja, 1995):

\section{Notations}

- Indices:

$\circ \mathrm{i}=1, \ldots, \mathrm{k}$ index of materials,

$\circ \mathrm{j}=1, \ldots, \mathrm{n}$ index of suppliers,

$\circ \mathrm{t}=1, \ldots, \mathrm{m}$ index of time periods.

○ $\mathrm{Z}=1, \ldots, \mathrm{Z}$ index of transport truck

\section{- Parameters:}

$\mathrm{W}_{\mathrm{j}}$; final weight of $\mathrm{i}^{\text {th }}$ supplier,

$\mathrm{C}_{\mathrm{jt}}$ capacity of $\mathrm{j}^{\text {th }}$ supplier in period $t$,

$\mathrm{D}_{\text {it }}$ demand materials for the planning period,

Pijt: purchase price of material $i$ from supplier $j$ in period $t$,

$\mathrm{A}_{\mathrm{j}}$ :Aggregate ordering cost of $j^{\text {th }}$ supplier

$\lambda$ : The periodic rate average of price increase in period $t$ compared to period $t-1$

B: minimum amount that a supplier may be ordered

$\mathrm{M}_{\mathrm{t}}$ : Maximum storage capacity in each period

$\mathrm{F}_{\mathrm{jz}}$ : Transportation costs from supplier $j$ with z-type transport truck

$\mathrm{r}$ : holding cost rate is the percentage of value-priced materials. 


\section{Decision variables:}

$\mathrm{X}_{\mathrm{ijt}}$ : ordering size of material $\mathrm{i}$ supplied from supplier $\mathrm{j}$ in period $\mathrm{t}$, $\mathrm{L}_{\mathrm{ijt}}$ : Additional material of type $\mathrm{i}$ of supplier $\mathrm{j}$ is the remainder of the period $t$, $\mathrm{N}_{\mathrm{jtz}}$ : Number of transit from supplier $\mathrm{j}$ in period $\mathrm{t}$ with z-type transport truck, $\mathrm{Y}_{\mathrm{jt}}$ : Binary variables to select or deselect supplier $\mathrm{j}$ in period $\mathrm{t}$.

\section{Objective functions:}

TVP: As $\mathrm{w}_{\mathrm{j}}$ and $\mathrm{X}_{\mathrm{ijt}}$ denote the normal weights of the suppliers and the quantity of purchased material from the jth supplier in period $t$, respectively, and the following objective function is designed to maximize the total value of purchasing:

$\max (T V P)=\sum_{i=1}^{k} \sum_{j=1}^{n} \sum_{t=1}^{m} w_{j} X_{i j t}$

Logistics cost: The sum of the annual material cost, annual order cost, annual holding cost and Annual transportation cost should be minimized; therefore,

$$
\begin{aligned}
\min (\mathrm{TAPC})= & \sum_{j=1}^{\mathrm{n}} \sum_{\mathrm{t}=1}^{\mathrm{m}} \mathrm{A}_{\mathrm{j}} \mathrm{Y}_{\mathrm{jt}}+\sum_{i=1}^{k} \sum_{j=1}^{n} \sum_{t=1}^{m} P_{i j t} X_{i j t}+\sum_{j=1}^{\mathrm{n}} \sum_{\mathrm{t}=1}^{\mathrm{m}} \sum_{\mathrm{z}=1}^{3} \mathrm{~F}_{\mathrm{jz}} \mathrm{N}_{\mathrm{jtz}} \\
& +\frac{1}{2} \sum_{i=1}^{k} \sum_{j=1}^{n} \sum_{t=1}^{m} r\left[P_{i j t} X_{i j t}+P_{i j t-1} L_{i j t-1}\right]
\end{aligned}
$$

\section{Constraints}

The constraints of the problem are formulated as follows:

Capacity constraints: As supplier $j$ can provide up to $C i$ units of the material and its order quantity in period $t\left(\mathrm{X}_{\mathrm{ijt}}\right)$ should be equal or less than its capacity, these constraints are,

$\sum_{i=1}^{k} X_{i j t} \leq C_{j t} Y_{j t} \quad$ for all $j$ and $t$

Demand constraint: As sum of the assigned order quantities to $n$ suppliers and carried quantities from the preceding period should meet the buyer's demand:

$\sum_{j=1}^{n} X_{i j t}+L_{i j t-1}-L_{i j t}=D_{i t} \quad$ for all $i$ and $t$

minimum order constraint: Several reasons (eg, transportation) is the creation of this constraint. This constraint indicates that the aggregate amount of the order must be greater than $\mathrm{B}$. these constraints are,

$\left(\sum_{i=1}^{k} X_{i j t}-B\right) Y_{j t}+\left(B-\sum_{i=1}^{k} X_{i j t}\right)\left(1-Y_{j t}\right) \geq 0$ for all $j$ and $t$ 
Storage Capacity constraint: Storage capacity is usually different for different materials that have been considered in the model.

$\sum_{i=1}^{k} \sum_{j=1}^{n} X_{i j t}+L_{i j t-1}-L_{i j t} \leq M_{t}$ for all $t$

Transportation constraints: This model is used to transport materials of different transport devices. This constraints show the number of shipped with every device. capacities of devices are 12,000 and $6,000 \mathrm{~kg}$.

$\sum_{\mathrm{i}=1}^{\mathrm{k}} \mathrm{X}_{\mathrm{ijt}}-\sum_{\mathrm{z}=1}^{\mathrm{z}} \mathrm{c}_{\mathrm{z}} \mathrm{N}_{\mathrm{jtz}} \leq 0$ for all $\mathrm{j}, \mathrm{t}$

$\mathrm{X}_{\mathrm{ijt}} \geq 0 \quad \mathrm{~L}_{\mathrm{ijt}} \geq 0 \quad \forall \mathrm{i}, \mathrm{j}, \mathrm{t}$

$\mathrm{Y}_{\mathrm{jt}}=0$ or 1

$\mathrm{N}_{\mathrm{jtz}} \geq 0$ and integer value

\subsubsection{Select the appropriate MOMINLP techniques to solve the model}

In order to solve the model, the goal programming method is applied. This method is described briefly in the case study.

\section{A case study}

This case study proposes a two-stage mathematical model to select suppliers and their orders allocations given a number of tangible and intangible criteria. In the first stage, three different suppliers that produce the PVC granules lof a cable plant in Iran are evaluated based on FANP and FVIKOR. In the second stage of the model, the weights computed by integrated FANP and FVIKOR serve as coefficients in the first objective function of the multi-period MOMINLP model.

The second objective calculates the cost of logistics to find efficient set of 6.1. Define the criteria for supplier selection For the evaluation process of the suppliers, 16 different criteria are defined under the 4 merits (Fig. 1.) by a team from the purchasing department. Then, build ANP model and determine the relationships.

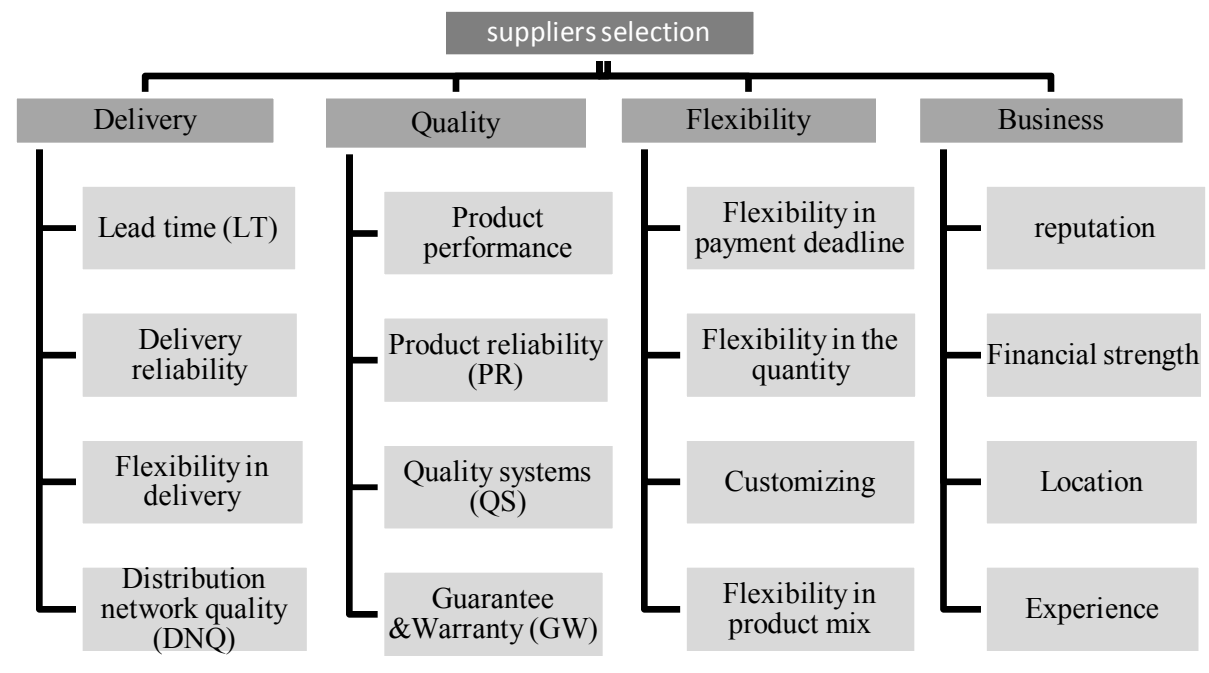

Fig. 1. Supplier Section Criteria 


\subsection{Calculate the weights of the criteria}

After the first step, paired comparisons to calculate the weights of the criteria are performed by the personnel from the purchasing department and the comparison results are combined by geometric mean. After all the cluster comparisons, the weights are calculated (see Table. 3).

Table 3

Fuzzy Weights Criteria

\begin{tabular}{|c|c|c|c|c|c|c|c|c|c|}
\hline criteria & sub.c & low & med & high & criteria & sub.c & low & med & high \\
\hline \multirow{4}{*}{ Quality } & PP & 0.1896 & 0.4636 & 1.0000 & \multirow{4}{*}{ flexiblity } & PD & 0.0445 & 0.2308 & 0.7506 \\
\hline & PR & 0.1197 & 0.3907 & 0.9397 & & Q & 0.0117 & 0.1613 & 0.6514 \\
\hline & QS & 0.0388 & 0.1802 & 0.5528 & & $\mathrm{C}$ & 0.0000 & 0.1470 & 0.6256 \\
\hline & QW & 0.0136 & 0.1196 & 0.4409 & & PM & 0.0018 & 0.1397 & 0.5741 \\
\hline \multirow{4}{*}{ Delivery } & LT & 0.1467 & 0.4294 & 0.9903 & \multirow{4}{*}{ Business } & $\mathrm{R}$ & 0.0744 & 0.1822 & 0.4645 \\
\hline & DR & 0.0608 & 0.2544 & 0.7371 & & FS & 0.0660 & 0.1687 & 0.4453 \\
\hline & FD & 0.0361 & 0.1835 & 0.5742 & & $\mathrm{~L}$ & 0.0653 & 0.1663 & 0.4440 \\
\hline & DNQ & 0.0612 & 0.2865 & 0.8258 & & $\mathrm{E}$ & 0.0695 & 0.1776 & 0.4645 \\
\hline
\end{tabular}

\subsection{Compute the overall score of each supplier}

The decision makers implement the linguistic rating variables demonstrated in Table 3 to calculate the ratings of suppliers with respect to each criterion. The ratings and overall scores of the 3 suppliers by the decision makers under the various criteria are shown in Table 4.

\section{Table 4}

Overall score of each supplier

\begin{tabular}{lllll}
\hline Supplier & low & med & high & Crisp Score \\
\hline S1 & 0.4765 & 0.7257 & 0.8974 & 0.7127 \\
S2 & 0.5046 & 0.6395 & 0.8227 & 0.6475 \\
S3 & 0.7906 & 0.9162 & 0.9579 & 0.9022 \\
\hline
\end{tabular}

\subsection{MOMINLP model and solution process}

This MOMINLP model is built on for a real-life problem via 3 suppliers and 3 periods and 3 materials. The requirements of which are as follows: Information about demand, prices, capacity of suppliers and ordering costs of different suppliers, Transport costs from different suppliers with different transport vehicle, respectively placed in the Tables. 5. Moreover, holding cost rate for planning period (r) is $4 \%$ of unit price.

Table 5

Demand, prices, capacity, ordering and transportation costs

\begin{tabular}{lcccc}
\hline \multirow{2}{*}{ Pve granules } & \multicolumn{3}{c}{ Supplier } & Demand for every period \\
\cline { 2 - 4 } & $\mathbf{1}$ & $\mathbf{2}$ & $\mathbf{3}$ & 100000 \\
\hline $\mathbf{1}$ & 17500 & 17500 & 18000 & 90000 \\
$\mathbf{2}$ & 18000 & 19000 & 19200 & 30000 \\
$\mathbf{3}$ & 22100 & 23500 & 24000 & \\
\hline $\boldsymbol{\lambda}$ & $6 \%$ & $5 \%$ & $5.5 \%$ \\
$\mathbf{C a p a c i t y}$ & 110000 & 80000 & 110000 \\
$\mathbf{A}_{\mathbf{j}}$ & $\mathbf{1}$ & 3000000 & 2000000 & 1500000 \\
$\mathbf{F}_{\mathbf{j}}$ & $\mathbf{2}$ & 5500000 & 2500000 & 1000000 \\
\hline
\end{tabular}


In order to solve the model, goal programming is used. The weights of objective functions are 0.4 and 0.6 , respectively. The steps are as follows: I. Determining the goals: For this, the model is solved with each of the objective functions. Therefore, maximum level of TVP and minimum level of TIC are 560662 and 13213530000.

II. The objective functions are converted to constraint, as a follows:

TVP: $Z_{1}+d_{1}^{-}-d_{1}^{+}=$goal $_{1}$

$T c P: Z_{2}+d_{2}^{-}-d_{2}^{+}=$goal $_{2}$

where $d_{i}^{+}$represent the positive components, $d_{i}^{-}$represent the negative components and $d_{i}^{-}, d_{i}^{+} \geq 0$

III. Creating new objective function, In order to minimum unfavorable variable, as a follows:

$\min w_{1} d_{1}^{-}+w_{2} d_{2}^{+}$

IV. Solving new model with respect to all constraint. This model is solved by lingo 8 and results of the model can be seen in Table. 6 .

Table 6

Results of the proposed model

\begin{tabular}{lllll}
\hline Suppliers & Orders & & & \\
\hline 1 & $\mathrm{X}_{211}=50000$ & $\mathrm{X}_{311}=58000$ & $\mathrm{X}_{212}=76000$ & $\mathrm{X}_{312}=32000$ \\
2 & $\mathrm{X}_{121}=80000$ & $\mathrm{X}_{122}=78000$ & $\mathrm{X}_{123}=72000$ & \\
3 & $\mathrm{X}_{131}=70000$ & $\mathrm{X}_{231}=40000$ & $\mathrm{X}_{232}=36000$ & $\mathrm{X}_{233}=68000$ \\
\hline Objective functions value & $\mathrm{TVP}=525330$ & & $\mathrm{TCP}=13243530000$ \\
\hline
\end{tabular}

\section{Conclusions}

In the current environment, supplier selection and order allocation decisions are some of the most important parts in supply chain management, which have gained importance increasingly in the globalization process. Selecting right suppliers significantly reduces the material purchasing costs and improves corporate competitiveness. Most of the companies can improve their competitive advantage by means of good supplier management. Hence, supplier selection should be performed by a systematic and scientific approach. During the supplier selection process, the purchasing manager should take into consideration strategic and operational factors as well as tangible and intangible factors.

In this paper, we proposed a two-stage integrated approach to select suppliers and determine their shipment allocations. In the first stage, three different suppliers that produce the PVC granules of a cable plant are evaluated by using integrated FANP and FVIKOR with 16 criteria. In the second stage, the weights computed by FVIKOR serve as coefficients of the TVP and inventory costs design the MOMINLP model. This applied model optimizes PVC granules orders in a cable plant (Table. 6).

\section{References}

Aksoy, A., \& Öztürk, N. (2011). Supplier selection and performance evaluation in just-in-time production environments. Expert Systems with Applications, 38(5), 6351-6359.

Aghajani Bazzazi, A., Osanloo, M., \& Karimi, B. (2011). Deriving preference order of open pit mines equipment through MADM methods: Application of modified VIKOR method. Expert Systems with Applications, 38(3), 2550-2556. 
Amid, A., Ghodsypour, S. H., \& O’Brien, C. (2009). A weighted additive fuzzy multiobjective model for the supplier selection problem under price breaks in a supply chain. International Journal of Production Economics, 121(2), 323-332.

Amid, A., Ghodsypour, S. H., \& O’Brien, C. (2011). A weighted max-min model for fuzzy multiobjective supplier selection in a supply chain. International Journal of Production Economics, 131(1), 139-145.

Amin, S. H., Razmi, J., \& Zhang, G. (2011). Supplier selection and order allocation based on fuzzy SWOT analysis and fuzzy linear programming. Expert Systems with Applications, 38(1), 334-342.

Awasthi, A., Chauhan, S. S., Goyal, S. K., \& Proth, J. M. (2009). Supplier selection problem for a single manufacturing unit under stochastic demand.International Journal of Production Economics, 117(1), 229-233.

Bache, J., Carr, R., Parnaby, J., \& Tobias, A. M. (1987). Supplier development systems. International Journal of Technology Management, 2(2), 219-228.

Bellman, R. E., \& Zadeh, L. A. (1970). Decision-making in a fuzzy environment.Management science, 17(4), B-141.

Çelebi, D., \& Bayraktar, D. (2008). An integrated neural network and data envelopment analysis for supplier evaluation under incomplete information. Expert Systems with Applications, 35(4), 16981710.

Chen, L. Y., \& Wang, T. C. (2009). Optimizing partners' choice in IS/IT outsourcing projects: The strategic decision of fuzzy VIKOR. International Journal of Production Economics, 120(1), 233242.

Chen, K. L., Chen, K. S., \& Li, R. K. (2005). Suppliers capability and price analysis chart. International Journal of Production Economics, 98(3), 315-327.

Choi, T. Y., \& Hartley, J. L. (1996). An exploration of supplier selection practices across the supply chain. Journal of operations management, 14(4), 333-343.

Chung, S. H., Lee, A. H., \& Pearn, W. L. (2005). Product mix optimization for semiconductor manufacturing based on AHP and ANP analysis. The International Journal of Advanced Manufacturing Technology, 25(11-12), 1144-1156.

Dickson, G. W. (1966). An analysis of vendor selection systems and decisions. Journal of purchasing, 2(1), 5-17.

Dobler, D. W., Burt, D. N., \& Lee, L. (1990). Purchasing and materials management: Text and cases (pp. 95-112). New York: McGraw-Hill.

Gwo-Hshiung, T., Tzeng, G. H., \& Huang, J. J. (2011). Multiple attribute decision making: Methods and applications. Chapman \& Hall.

Ha, S. H., \& Krishnan, R. (2008). A hybrid approach to supplier selection for the maintenance of a competitive supply chain. Expert Systems with Applications,34(2), 1303-1311.

Haleh, H., \& Hamidi, A. (2011). A fuzzy MCDM model for allocating orders to suppliers in a supply chain under uncertainty over a multi-period time horizon. Expert Systems with Applications, 38(8), 9076-9083.

Herrera, F., \& Herrera-Viedma, E. (2000). Linguistic decision analysis: steps for solving decision problems under linguistic information. Fuzzy Sets and systems, 115(1), 67-82.

$\mathrm{Hu}$, J. (2004). Supplier selection determination and centralized purchasing decisions.

Khouja, M. (1995). The use of data envelopment analysis for technology selection. Computers \& Industrial Engineering, 28(1), 123-132.

Kilincci, O., \& Onal, S. A. (2011). Fuzzy AHP approach for supplier selection in a washing machine company. Expert Systems with Applications, 38(8), 9656-9664.

Krajewski, L. J., Ritzman, L. P., \& Malhotra, M. K. (2007). Operations management: processes and value chains.

Kumar, M., Vrat, P., \& Shankar, R. (2006). A fuzzy programming approach for vendor selection problem in a supply chain. International Journal of Production Economics, 101(2), 273-285. 
Lee, A. H. (2009). A fuzzy supplier selection model with the consideration of benefits, opportunities, costs and risks. Expert systems with applications,36(2), 2879-2893.

Liao, C. N., \& Kao, H. P. (2011). An integrated fuzzy TOPSIS and MCGP approach to supplier selection in supply chain management. Expert Systems with Applications, 38(9), 10803-10811.

Lin, R. H., Chuang, C. L., Liou, J. J., \& Wu, G. D. (2009). An integrated method for finding key suppliers in SCM. Expert Systems with Applications, 36(3), 6461-6465.

Mohanty, R. P., Agarwal, R., Choudhury, A. K., \& Tiwari, M. K. (2005). A fuzzy ANP-based approach to R\&D project selection: a case study. International Journal of Production Research, 43(24), 5199-5216.

Ramik, J. (2007). A decision system using ANP and fuzzy inputs. International Journal of Innovative Computing, Information and Control, 3(4), 825-837.

Roa, C. P., \& Kiser, G. E. (1980). Educational buyers' perceptions of vendor attributes. Journal of Purchasing Material Management, 16, 25-30.

Rezaei, J., \& Davoodi, M. (2011). Multi-objective models for lot-sizing with supplier selection. International Journal of Production Economics, 130(1), 77-86.

Shemshadi, A., Shirazi, H., Toreihi, M., \& Tarokh, M. J. (2011). A fuzzy VIKOR method for supplier selection based on entropy measure for objective weighting. Expert Systems with Applications, 38(10), 12160-12167.

Talluri, S., \& Narasimhan, R. (2004). A methodology for strategic sourcing.European Journal of Operational Research, 154(1), 236-250.

Tong, L. I., Chen, C. C., \& Wang, C. H. (2007). Optimization of multi-response processes using the VIKOR method. The International Journal of Advanced Manufacturing Technology, 31(11-12), 1049-1057.

Tsai, Y. L., Yang, Y. J., \& Lin, C. H. (2010). A dynamic decision approach for supplier selection using ant colony system. Expert Systems with Applications,37(12), 8313-8321.

Ustun, O., \& Demirtas, E. A. (2008). Multi-period lot-sizing with supplier selection using achievement scalarizing functions. Computers \& Industrial Engineering, 54(4), 918-931.

Van der Rhee, B., Verma, R., \& Plaschka, G. (2009). Understanding trade-offs in the supplier selection process: The role of flexibility, delivery, and value-added services/support. International Journal of Production Economics, 120(1), 30-41.

Vinodh, S., Anesh Ramiya, R., \& Gautham, S. G. (2011). Application of fuzzy analytic network process for supplier selection in a manufacturing organisation. Expert Systems with Applications, 38(1), 272-280.

Wang, G., Huang, S. H., \& Dismukes, J. P. (2004). Product-driven supply chain selection using integrated multi-criteria decision-making methodology. International journal of production economics, 91(1), 1-15.

Willis, T. H., Huston, C. R., \& Pohlkamp, F. (1993). Evaluation measures of just-in-time supplier performance. Production and Inventory Management Journal, 34, 1-1.

Wu, H. Y., Tzeng, G. H., \& Chen, Y. H. (2009). A fuzzy MCDM approach for evaluating banking performance based on Balanced Scorecard. Expert Systems with Applications, 36(6), 10135-10147.

Wu, W. Y., Sukoco, B. M., Li, C. Y., \& Chen, S. H. (2009). An integrated multi-objective decisionmaking process for supplier selection with bundling problem. Expert Systems with Applications, 36(2), 2327-2337.

Yüksel, İ., \& Dagdeviren, M. (2007). Using the analytic network process (ANP) in a SWOT analysis-A case study for a textile firm. Information Sciences, 177(16), 3364-3382. 